\title{
Shared Patron-Driven Acquisition Within a Consortium: the OCUL PDA Pilot
}

\section{Kate Davis}

University of Toronto

\section{Lei Jin}

Ryerson University

\section{Colleen Neely}

Western University

\section{Harriet Rykse}

Carleton University

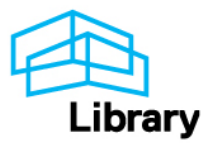




\title{
Shared Patron-Driven Acquisition Within a Consortium: the OCUL PDA Pilot
}

\author{
Kate Davis ${ }^{\mathrm{a} 1}$, Lei Jin ${ }^{\mathrm{b}}$, Colleen Neely ${ }^{\mathrm{c} 2}$, Harriet Rykse ${ }^{\mathrm{d}}$
}

\begin{abstract}
In September 2010 members of the Ontario Council of University Libraries (OCUL) participated in a Patron Driven Acquisitions (PDA) pilot to determine how this purchasing model might be adapted to a consortium. OCUL understood that developing a model that would allow patrons to purchase titles for different collections would be complicated. Careful thought went into balancing the needs of individual members with the needs of the consortium. This paper describes the project and examines the results from three distinct perspectives in the hopes of gaining a better understanding of the challenges and opportunities of PDA at a consortial level.
\end{abstract}

\section{Keywords}

patron-driven acquisition; consortium; Ontario Council of University Libraries (OCUL); ebrary; purchase-on-demand acquisition; collaborative collection development

\section{Introduction}

Patron Driven Acquisition allows a library to offer a wide selection of material to their users without making a purchase until the item has been requested or used. In a print PDA model, the items are ordered for purchase when they are requested through Interlibrary Loan (ILL). In an electronic model, items are triggered for purchase when they have been opened one or more times or remain open for a specified amount of time. The trigger for purchase depends on the arrangement that the library and vendor have agreed to.

Collaborative Collection Development (CCD) refers to a collection practice in which a consortial group of libraries purchase single or a limited number of copies to share among all the libraries in the consortium. In a print CCD model ILL is used to share the purchased item among libraries. For electronic material purchased through a CCD model, access is made available at a level agreed to by the libraries and the vendor, to users at all member institutions.

While it is not difficult to locate literature describing the benefits and challenges of both PDA and CCD, there is very little literature describing the possibility of linking these two models. Mallery and Theus (2012) suggest several possibilities for CCD in the future including ". . . advances in technologies for electronic resource sharing, such as e-book collections. .." Booth and O'Brien (2011) describe how their institution combined the CCD and PDA models for print resources and ask the question "What sorts of models exist to apply these linked strategies to e-books?" The pilot project described below presents an initial effort to answer this question.

\section{Background}

OCUL is a consortium of Ontario's twenty-one university libraries and serves a total 
population of 420,000 faculty and students. OCUL enhances information services in Ontario not only through collective purchasing, but also through its Scholars Portal, a shared technology infrastructure that locally archives and provides access to information resources collected and shared by member institutions. At the time of the pilot, Scholars Portal had recently released a new e-book platform, based on ebrary's ISIS technology, that aimed to aggregate and ensure permanent access to collections of e-books from a variety of content providers on locally hosted and maintained servers and to provide OCUL with opportunities to explore new models for the acquisition and licensing of ebooks. At the same time, many OCUL members had been experimenting with PDA at the institutional level. While these forays into PDA by individual institutions were generally successful, there was interest in determining if a consortial PDA model would allow the community to take advantage of volume discounts and the benefits offered by locally hosting e-books on Scholars Portal.

\section{Developing a Model}

OCUL started exploring the possibility of a PDA pilot with ebrary at the beginning of 2010. It made sense to partner with ebrary as OCUL had been working closely with them on the development of the Scholars Portal e-book platform, they were experimenting with PDA on their own platform and they had agreed to work with publishers on behalf of OCUL to acquire the rights to locally host and archive purchased titles. While the potential benefits of a consortial PDA were clear both to OCUL and to ebrary, the challenges of accommodating the needs of OCUL member institutions with very different academic focuses and with student populations that range in size from 700 to 80,000 were also clear. The first hurdle was to develop a model that would take into account the large number of people this pilot would potentially reach and the diversity of OCUL institutions, ensuring that individuals from as many institutions as possible participated, that materials purchased were of interest to more than one institution and, that those materials did not duplicate existing collections. Further, the model had to allow students and faculty from different schools to have access to PDA titles in the absence of a joint catalogue.

At the time, ebrary was piloting a model in which a deposit account was created for an institution and a set of titles were made available to their users either through MARC records in the catalogue or simply on the ebrary platform. Five interactions with a title, defined as unique pages viewed, copied or printed, triggered a purchase and when an institution's available funds were depleted it could choose to refill the deposit account or end the pilot. OCUL started by tweaking this model, first, by increasing to 25 the number of interactions necessary to trigger a purchase and second, by increasing the number of single use copies of a title that would be purchased to share across participating institutions to four. OCUL also tried to introduce a mechanism into the 
model which would ensure that purchased titles had been used by more than one institution or that every institution participated in the purchase of at least one title. However, this proved impossible to do while still meeting publisher requirements. As the aim of the pilot was to better understand how PDA might work at a consortial level, OCUL decided to forego such a mechanism and instead closely analyze the results of the pilot to determine if such a mechanism was indeed necessary. Accordingly, ebrary agreed to create a number of specific reports that would facilitate this analysis.

Lastly, it was agreed that a dedicated ebrary channel would be created for the pilot and that MARC records pointing to this channel would be made available to patrons through their institution's OPAC. The only way to access the titles for the pilot would be through these catalogue records. Patrons would not be able to access them from their library's own individual ebrary channel.

\section{Creating a Title List}

Once a model had been agreed upon, the next task was to determine which titles would be included in the pilot. Ebrary provided a list of over 90,000 titles. A committee narrowed this list down considerably using selection criteria developed for the pilot. The

price ceiling was set at $\$ 200$, titles had to be in either English or French, and the imprint date had to be within the last 10 years (i.e. 2000-2010). Publishers' collections that had been purchased consortially prior to the pilot or that were deemed non-academic were removed. These initial cuts reduced the list to approximately 38,000 titles. Agreeing on these broad criteria was relatively simple; however, the list still included many books that were considered to be inappropriate for the pilot, such as titles that were originally an issue of a journal or part of a multivolume set or series. The committee was keen to remove these; however, it quickly became clear that finding them was a bit like finding a needle in a haystack. Moreover there was no effective way to identify titles that already existed in the collections of participating libraries. Since it was impossible to eliminate duplicates and serials before the pilot, ebrary agreed to reimburse OCUL for duplicates on the ebrary platform and to swap out any serial purchased once the pilot had ended. Accordingly, efforts were focused on analyzing the results of the pilot rather than further refining the list prior to the pilot.

\section{OCUL PDA Pilot}

OCUL members were sent a proposal that described the model that had been agreed to with ebrary and the costs to participate. These costs were relatively inexpensive and were based on FTE. The small schools (less than 10,000 FTE) contributed \$5,000; the medium ones (10,000-25,000 FTE) contributed \$10,000; and the large schools (over 25,000 FTE) contributed $\$ 15,000$. 16 of the 21 schools agreed to participate in the pilot and a total of $\$ 150,000$ was collected. 
Once a date to begin the pilot had been agreed upon, OCUL had to ensure that all 16 schools had MARC records for the 38,000 titles loaded and accessible in their catalogues for the morning of the launch. Since OCUL doesn't have a shared catalogue, accomplishing this required communication with, and cooperation on the part of the cataloguers at the participating libraries.

In mid-August, ebrary created a dedicated channel for the pilot, added the 38,000 titles to it, and sent the MARC records for these titles to OCUL. Staff at OCUL made the records available for downloading from the Scholars Portal wiki. Messages went out to participants letting them know that they could download the records at any time, but that they would need to keep them suppressed until the week before the launch. The week prior to the launch was a test week, giving everyone a chance to make sure that the records were loaded and that the links were working. Interactions that week didn't count toward purchases.

Member institutions were asked not to advertise the pilot so their patrons would be unaware that they were selecting materials for the OCUL libraries.

All 16 schools had the records loaded on time, and were ready for the launch. The pilot went live on September 20. On September 28, ebrary reported that the $\$ 150,000$ was spent. A total of 467 unique titles were purchased during the pilot and, as per the agreement with ebrary, four copies of each title are made available to the participating institutions.

On October 3, access was cut off to the dedicated ebrary channel. The concern now was that patrons were going to start reporting dead links or would find that a book that they had been reading had disappeared. The participating libraries needed to get the records for the purchased titles loaded as quickly as possible. Between October 4 and 7 ebrary moved the purchased titles over to the participants' channels and made the MARC records ready for each school (16 individual files). The original batch of 38,000 records was removed and the records for the 467 purchased titles were loaded into each institution's catalogue.

\section{OCUL PDA Pilot - Consortial Perspective}

The preparation for the pilot was a lot more work than anticipated. Developing a workable model and agreeing on a title list took over ten months and significant staff time. OCUL staff also acted as intermediaries between ebrary and staff at participating institutions, so fielding problem reports took a lot of time, as did coordinating the loading and unloading of MARC records. This was exacerbated by the large number of titles and the speed with which the money was spent once the records were made available to the public. The speed at which the pilot progressed not only caused problems for cataloguing staff at some institutions, but made it clear that the number of titles available for purchase and the amount of money available for the project were not appropriately balanced. 
There were also a number of technical issues such as links to titles not working. Many of these were discovered by librarians during the test week and were corrected prior to the launch of the pilot; however, others did not surface until later and had a significant effect on the results of the project. Specifically, problems with the custom reports ebrary had promised made it much more difficult to properly analyze what had happened on the days the records were available to the public. This can be traced back to the fact that although there were many institutions participating, the trial was set up as a single institution on ebrary. For ebrary to produce accurate reports at the level of detail OCUL had hoped for would have required significant technical changes to their platform.

In spite of these issues, the analysis that was completed showed that concerns about the inability of the model to ensure participation from all institutions were unfounded. Indeed, users from every institution triggered at least one book and $48 \%$ of titles were triggered by users from more than one institution (see Figure 1). However, a number of serials were purchased and had to be swapped for different titles and larger institutions acquired a significant amount of duplicate content.

Figure 1: Titles Triggered by Number of Schools

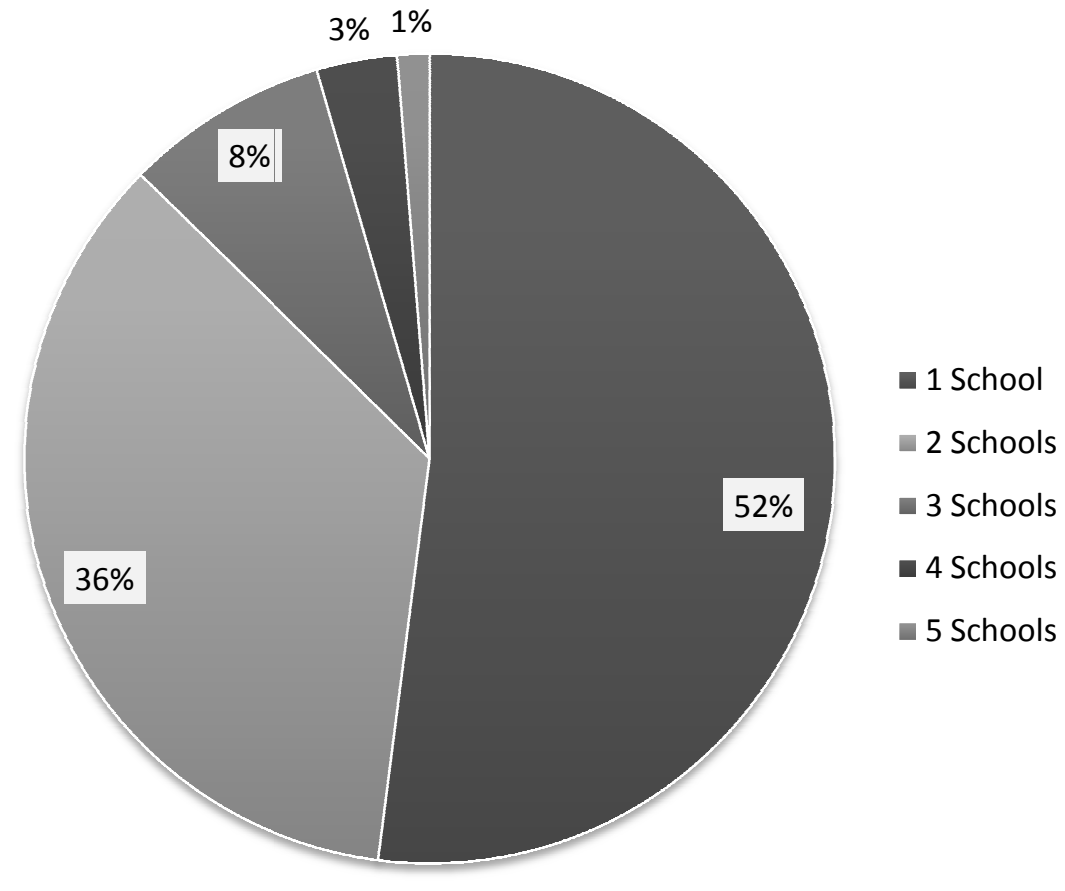

Participants were able to take advantage of volume discounts and acquired many valuable books for a relatively low cost. The average price of a PDA title was $\$ 80.00$; however, libraries, depending on their original contribution, paid an average of $\$ 10.70$ (small), $\$ 21.40$ (medium), and \$32.00 (large) per title. 
Both the publisher and subject distribution of the purchased titles were correlated to the number of titles that were accessible to users. In terms of publisher distribution, $45 \%$ of titles purchased were Wiley publications, followed by Elsevier and McGraw-Hill (12\% each) (see Figure 2). These numbers closely matched the percentage of publishers' titles that were available in the pilot.

Figure 2: PDA Publisher Distribution of Purchased Titles

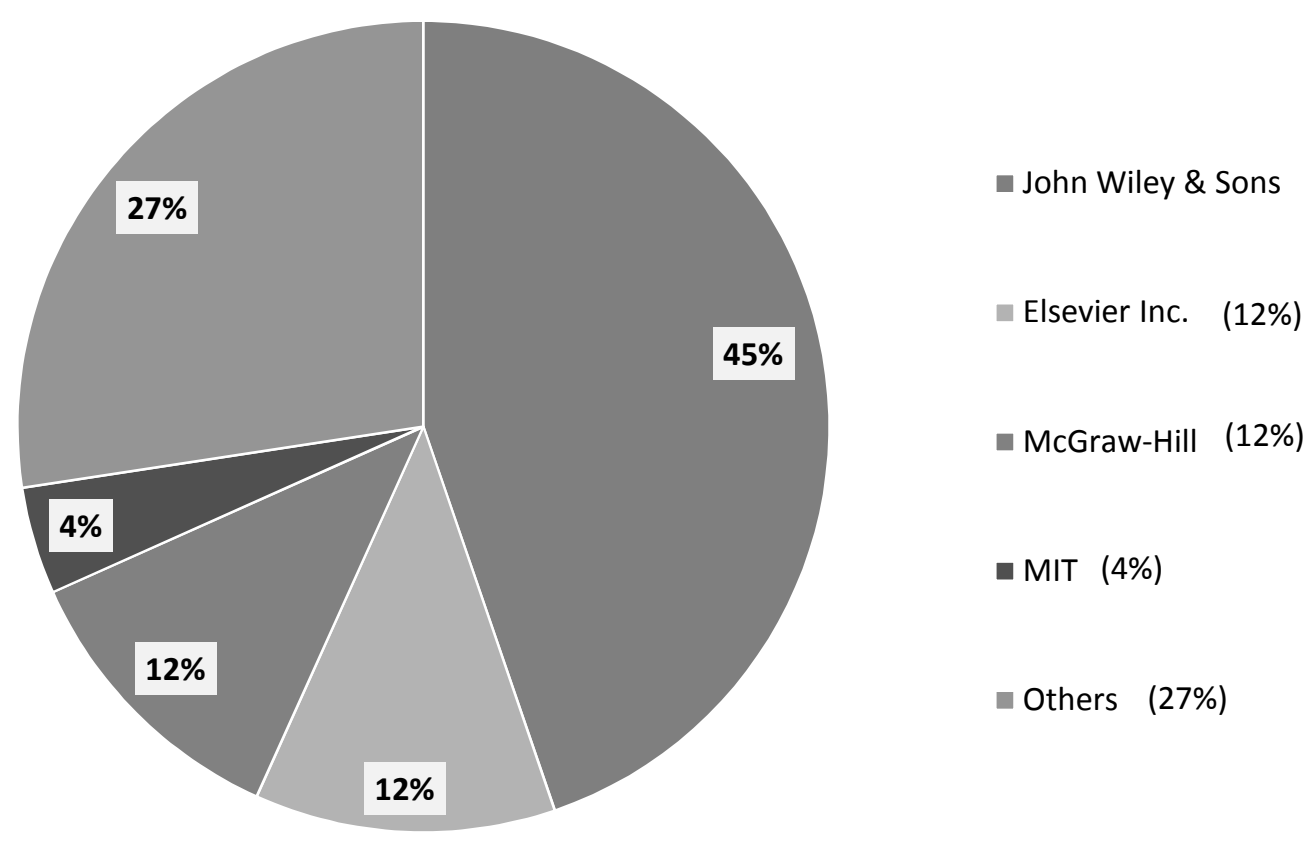

The subjects of the titles purchased also matched the overall subject distribution of the titles that were available in the pilot. $18 \%$ of the titles that were purchased were business and economics books (see Figure 3). 
Figure 3: Subject Breakdown

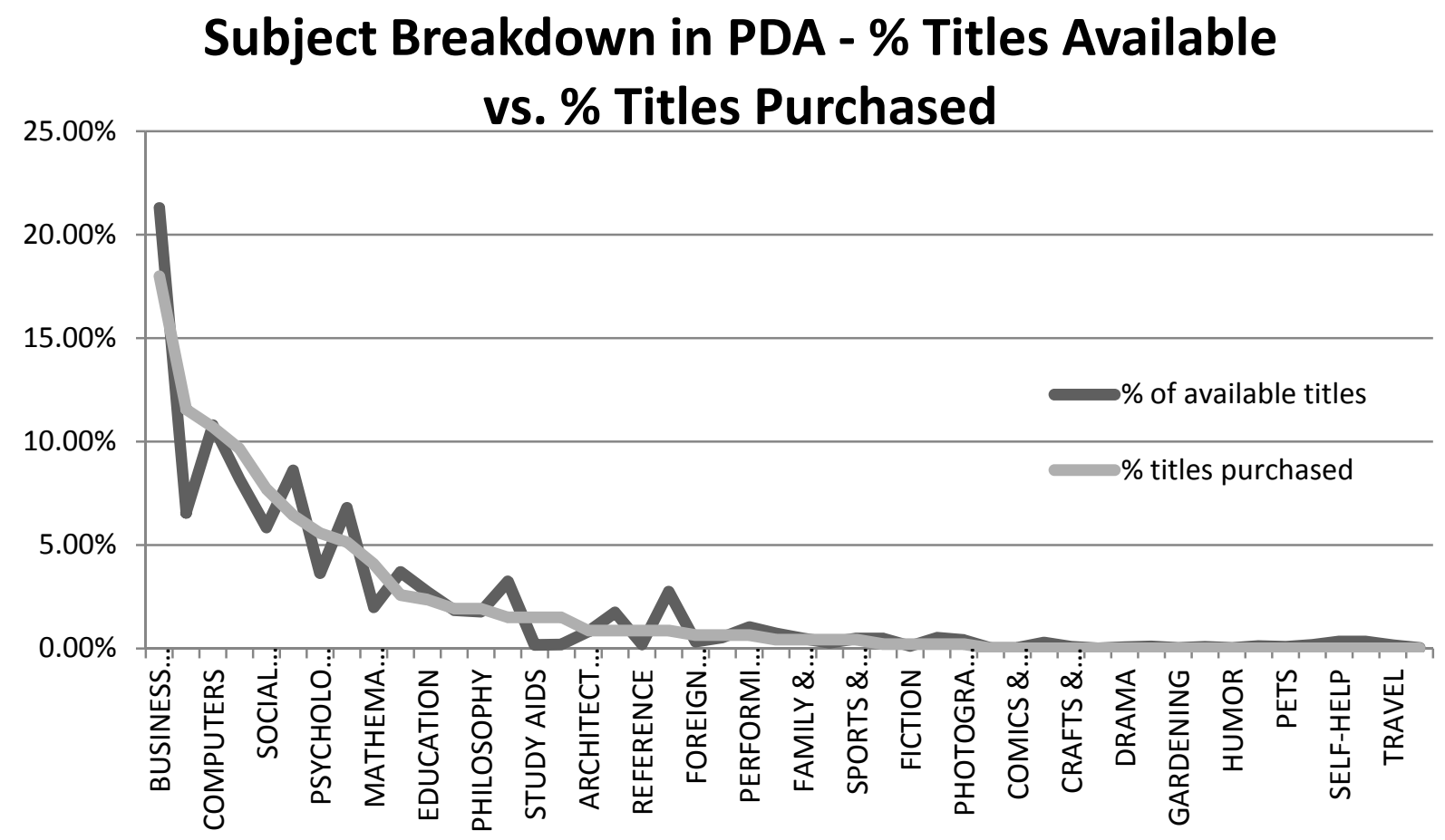

Lastly, although it took quite a while to secure the local loading rights for the PDA titles, all the titles were loaded to the Scholars Portal e-book platform in December 2011 and are now properly archived and can be accessed as part of the Scholars Portal collection.

Additional results of the pilot are available at: http://spotdocs.scholarsportal.info/x/94A5BQ

\section{OCUL PDA Pilot - Institutional Perspectives Western University}

Western University is a large medical/post-doctoral institution with a student population of over 34,000. Since 2007 Western Libraries has been experimenting with versions of the PDA model offered by different vendors. Our experience with single institution PDA trials has confirmed that this method of acquisition is a viable addition to our existing acquisitions methods. The OCUL PDA trial offered Western Libraries an opportunity to experiment with PDA in a new way.

Based on previous experiences with PDA there were some questions about the large size of the collection proposed for the OCUL PDA trial as it represented a fairly significant amount of duplicate content for Western Libraries. Despite the potential for duplication, this experiment provided Western Libraries a valuable opportunity for proof-of-concept for PDA at a consortium level. 


\section{Running the pilot at Western}

Western Libraries uses the Innovative Interfaces Inc. Millennium ILS. Before the PDA records for the trial were loaded a note was added in the 856 and 039 Marc fields identifying them as part of the OCUL PDA trial. This made it possible to easily identify and suppress just this group of records and to quickly remove the records from the catalogue at the end of the trial.

At the completion of the trial the full records for the purchased titles were loaded into the catalogue with a note in the 039 Marc field and in the check-in record to identify the title as part of the OCUL PDA trial. This tagging, while not strictly necessary, allows easy identification of the PDA titles and continued tracking of use. Since Western Libraries takes a single record approach in the catalogue, records were merged if necessary.

Western Libraries technical services staff had no difficulties loading the records for the PDA trial and keeping them suppressed until the trial start date. Removing the records at the end of the trial did not pose any challenges technically, but did cause some confusion to users who could no longer locate a title they had used the day before. Although this required communication with front-line service staff and, through them, the users, the problem would better be described as a minor irritant than a major difficulty. If future trials are considered, a plan to smooth the transition from end of trial to loading of purchased content would be important to consider.

\section{Results for Western}

Of the 467 PDA titles purchased for the consortium, 169 titles represented unique content for Western Libraries while 278 titles duplicated content already owned in print and/or electronic format. 246 titles represented new electronic content although many of these had print duplicates. Counting only the 169 unique titles purchased the average cost per book was $\$ 89$. Although Western Libraries follows a policy to avoid duplication of content if possible and this amount of duplication is not typically considered acceptable, the low average cost for unique titles made the trial worth the investment of time and money. Future OCUL PDA trials would need to ensure that the majority of content available for PDA does not duplicate content already held in our collection. Limiting the trial to only a front list collection would be one way to do this.

A review of OCUL PDA title use at Western was limited to the unique 169 titles in order to gain a sense of how heavily material selected by the consortium members was used locally by Western students and faculty. Of the unique titles over half $(63 \%)$ have been used at least once since the title was purchased in September 2010 and 17\% have been used more than 10 times (Table 1). In light of the fact that the 16 participating institutions represent a broad range of student populations and program scope, this amount of use seems to represent a fairly reasonable return on investment for the purchased titles. More analysis needs to be done in order to determine how this amount of use compares to the use of titles selected by librarians over the same period and in the same subject areas. Among the institutions that participated in this trial, Western may have an advantage in that it is one of the larger institutions with a correspondingly 
broader scope of research and teaching, which may increase the odds that the material purchased will find a reader. The corollary would be that, with a correspondingly larger collection, the odds of duplicating content were much greater.

Table 1: Use of 169 unique titles between September 2010 and March 2012

\begin{tabular}{|l|l|}
\hline Titles never used & $62(37 \%)$ \\
\hline Titles used at least once (user sessions) & $107(63 \%)$ \\
\hline Titles used more than 10 times & $29(17 \%)$ \\
\hline Titles used more than 100 times & $2(1 \%)$ \\
\hline
\end{tabular}

\section{Ryerson University}

Ryerson University is a fast growing institution with over 80 undergraduate and graduate programs, as well as the largest university-based continuing education school in Canada. Because of its downtown location and constant space demands, Ryerson Library has always focused on electronic resources as a collection development strategy and was eager to participate in this consortium-initiated PDA project.

\section{Running the pilot at Ryerson}

The pilot took approximately 4 weeks from the time the PDA records were loaded into the catalogue to when all the records for purchased titles were reloaded at the end of the trial. While the initial loading was relatively smooth, one small indexing issue with the first batch had significantly slow down the process run before it was corrected. A quick call to the ILS provider, resolved the issue and no further problems were encountered.

\section{Results for Ryerson}

Ryerson was pleased with the results of the pilot. Of the 467 books purchased, 338 titles, or $71 \%$ were unique to the collection; 115 duplicated titles in Ryerson's existing print collection; and 15 duplicated titles in the e-collection. Because Ryerson has a relatively small print collection, more unique content was acquired than for other similarly sized participants and accordingly the cost per unique title was only $\$ 29.58$. Of the 78 titles triggered by Ryerson patrons, 28 overlapped with the library's existing collection and 4 out of these 28 were already available as e-books. Approximately, $36 \%$ of the titles triggered by Ryerson patrons had duplicates in the existing collection while only $28 \%$ of all titles purchased represented duplicates in Ryerson's collection. This higher percentage of duplication selected by Ryerson's own users may be an indicator of the quality of librarian selected material and deserves further study.

The collection continues to be well used according to Ebrary's Counter Book Report 2, which shows $43 \%$ of all PDA e-book titles had at least 1 use in the first 6 months after purchase. For Ryerson-triggered titles, $80.7 \%$ had at least 1 use during the same time period, and this number goes up to $92.3 \%$ if use is counted for 17 months - up to March 2012 (Table 2). 
Table 2: Total Usage for Ryerson-triggered Titles (November 2010 - March 2012)

\begin{tabular}{|l|c|c|}
\hline Usage (section views) & Number of titles & Percentage \\
\hline Over 1000 & 14 & $18 \%$ \\
\hline Between $100-1000$ & 38 & $48.7 \%$ \\
\hline Between $10-100$ & 19 & $24.3 \%$ \\
\hline 5 and below & 7 & $9 \%$ \\
\hline
\end{tabular}

Circulation statistics of Ryerson-triggered duplicated titles before and after purchase were also considered. Among the 24 print duplicated titles, 10 titles $(41.7 \%)$ had circulated at least once in the year leading up to the project. In the year after the e-copy became available to the library, 19 titles, or $79 \%$, circulated at least once. It is interesting to see that the online availability of these high demand books does not lead to a decline of print circulation; on the contrary, patrons continue to use print copies. Information searching and browsing may start with the e-book version and further research needs to be undertaken to verify this.

Ryerson has come to the same conclusion as Western to limit duplicate content; the initial title list could be further trimmed by limiting the publication date to avoid older content. A smaller title list would also allow librarian mediation to exclude additional titles that fall out of scope. In general, this consortial project was a very positive experience for Ryerson, given the content purchased, the subsequent usage, and the low cost per unique title.

The OCUL PDA experience led to another PDA project at Ryerson in 2011. Some issues that came up during the OCUL pilot were addressed in the latter project. Ryerson continues to explore this collection strategy and anticipates that it will be adopted into our routine collection practices.

\section{Feedback from other participating institutions}

Informal input gathered from other participating institutions regarding the consortial PDA experience revealed that the technical requirements for loading and suppressing records prior to the trial and then reloading the purchased titles after the trial presented a challenge for several schools. The level of challenge seemed to be dependant on the ILS used by the institution.

A short survey requesting comments regarding the content of the purchased collection indicated that the perceived value of the purchased titles varied widely among institutions. The primary concerns centered around the amount of duplication with material already held in the school's collection, the wide date range for the collection and the value of the content as related to an institution's instructional programs and research. Smaller schools did not have as much duplication with existing collections but the content purchased was frequently outside the scope of their research and teaching. 
Four single user copies shared among 16 institutions appears to be a reasonable level of access as there have not been many turn-aways or complaints regarding the level of access.

Most schools agreed that the trial was a useful proof-of-concept for acquiring material in a consortial environment through a PDA program. In general, schools expressed willingness to participate in a second trial if some changes were made in the process as well as beginning with a smaller, more refined collection.

\section{Future PDAs at OCUL}

OCUL's PDA pilot was an innovative experiment that gave us both valuable insight and practical experience with which to approach any future PDA projects. If OCUL were to participate in a consortial PDA in the future, it would likely target a specific publisher or collection and be limited to front list titles to minimize duplication. The amount of money dedicated to such an endeavor would need to be proportionate to the collection size to ensure the trial could run for several months and local load rights would need to be secured before the launch of the project.

\section{Acknowledgements}

We would like to acknowledge the work of Dana Thomas, who was seconded to Scholars Portal as the Evaluation and Assessment Librarian. She analyzed the data received from ebrary and created the graphs in this paper.

\section{References}

Booth, H.A. \& O'Brien, K. (2011). Demand-driven cooperative collection development: three case studies from the USA. Interlending \& Document Supply, 39, 148-155.

Mallery, M. \& Theus, P. (2012). New Frontiers in Collaborative Collection Management. Technical Services Quarterly, 29, 101-112. 